\title{
Konsep normatif pendidikan keluarga muslim
}

\author{
Aris Munandar a,1, ${ }^{*}$, Suhartono ${ }^{\text {a,2 }}$, Fajar Mustaqim a,3 \\ a Sekolah Tinggi Ilmu Tarbiyah Madani Yogyakarta, Indonesia; \\ *1_arismunandarjogja@gmail.com; ${ }^{2}$ suhartono.abuhasna@gmail.com; 3 fajar.mustaqim@gmail.com \\ *Correspondent Author
}

KAT A KUNCI

Konsep normatif

Pendidikan

Keluarga muslim

\section{KEYWORDS}

Normative concept

Education

Muslim family

\section{ABSTRAK}

Keluarga merupakan unit terkecil dalam masyarakat yang dapat dijadikan anak tangga pertama untuk mencapai kebahagiaan hidup, baik di dunia maupun di akhirat. Guna tercapainya tujuan pendidikan keluarga dibutuhkan kerjasama, saling tolong-menolong dan saling nasehat-menasehati dalam kebaikan dan taqwa diantara anggota keluarga. Jenis penelitian ini tergolong penelitian pustaka (library research), karena semua yang digali adalah bersumber dari pustaka, memaparkan tentang pendidikan keluarga berdasarkan dalil baik dari Al qur'an maupun hadist-hadist Rasulullah Shalallahu'alaihiwasallam. Hasil penelitian ini menunjukkan bahwa; orang tua berkedudukan sebagai pengajar, sebagai pendidik, pembimbing dan sebagai pendidik yang utama diperoleh anak. Tujuan dari pendidikan keluarga muslim adalah menjaga anggota keluarga terutama istri dan anak-anaknya dari siksa api neraka dengan berusaha mengamalkan apa yang Allah peritahkan dan meninggalkan apa yang Allah larang. Keluarga merupakan tempat berlindung dari berbuat dosa dan hendaknya dalam keluarga menjaga diri dari yang haram, kunci keselamatan seseorang dari hal-hal yang merusak iman adalah betah tinggal di rumah. Kumpul keluarga merupakan cara paling efektif demi tercapainya tujuan pendidikan keluarga.

\section{The normative concept of Muslim family education}

The family is the smallest unit in society that can be used as the first rung to achieve happiness in life, both in this world and in the hereafter. In order to achieve the goal of family education, cooperation, mutual assistance and mutual advice are needed in kindness and piety among family members. This type of research is classified as library research, because everything that is excavated is sourced from libraries, describing family education based on the arguments from both the Al-quran and the hadiths of the Prophet Salallahu'alaihiwasallam. The results of this study indicate that; parents have the position of teaching, as educators, mentors and as educators who are primarily acquired by children. The purpose of Muslim family education is to protect family members, especially their wives and children, from the torments of hellfire by trying to practice what Allah commands and leaving what Allah forbids. The family is a place of refuge from sinning and in the family they should guard themselves from what is haram, the key to one's salvation from things that destroy faith is to feel at home. Family gatherings are the most effective way to achieve family education goals.

This is an open-access article under the CC-BY-SA license. 


\section{Pendahuluan}

Pendidikan keluarga merupakan pendidikan yang pertama dan utama dalam pembinaan agama seseorang(Safriana \& Khasanah, 2019). Keluarga diharapkan dapat menjadi motor pengerak dalam proses pendidikan. Hal ini berarti, oreantasi utama dalam keluaraga, harus mencerminkan nilai-nilai pendidikan Islam, sehingga seluruh rutinitas dalam keluarga tersebut, akan berdampak pada keberhasilan tujuan pendidikan.

Keluarga (kawula dan warga) dalam pandangan antropologi (Suyono, 2018)adalah suatu kesatuan sosial terkecil yang dimiliki oleh manusia sebagai makhluk sosial yang memiliki tempat tinggal dan ditandai oleh kerjasama ekonomi, berkembang, mendidik, melindungi, merawat dan sebagainya. Inti keluarga adalah ayah, ibu dan anak. Sedangkan yang dimaksud keluarga muslim (Sarbini, 2017)adalah keluarga yang mendasarkan aktivitasnya pada pembentukan keluarga yang sesuai dengan syariat Islam.

Keluarga merupakan unit terkecil dalam masyarakat(Dirgayunita, 2020) yang dapat dijadikan anak tangga pertama untuk mencapai kebahagiaan hidup, baik di dunia maupun di akhirat. Sebuah keluarga jika dikelola dengan baik berdasarkan syar`i akan dapat menempatkan anggota keluarga tersebut pada posisi terhormat dalam kehidupan bermasyarakat(Mawardi, 2017). Upaya pembinaan keluarga sakinah diawali dengan pembentukan pribadi masing-masing. Saling pengertian dan tahu akan tugas dan kewajiban masingmasing individu dalam keluarga. Tidak menggantungkan dan tidak menjadikan beban terhadap orang lain lebih lagi kepada keluarga sendiri.

Peran penting pendidikan keluarga dalam membentuk karakter anak juga diuraikan oleh Ki Hajar Dewantara, (Cahyani \& Suyadi, 2019)beliau menyatakan bahwa alam keluarga bagi setiap orang (anak) adalah alam pendidikan permulaan. Untuk pertama kalinya, orang tua (ayah maupun ibu) berkedudukan sebagai pengajar, sebagai pendidik, pembimbing dan sebagai pendidik yang utama diperoleh anak. Berbagai pendapat para ahli di atas, menunjukkan konsep pendidikan keluarga, harus hadir dalam praktek dan implementasi, yang dilaksanakan oleh orang tua (ayah ibu) melalui penanaman nilai-nilai pendidikan dalam keluarga.

Disisi lain menurut laporan Badan Pusat Statistik (BPS), menyatakan satu dari tiga perempuan usia 15-64 tahun pernah mengalami kekerasan fisik dan/atau seksual selama hidupnya(Krisnani \& Kessik, 2020), dan laporan CNN Indonesia tanggal 21 Desember 2016 yang menyatakan bahwa 25,86 persen kekerasan dalam rumah tangga di Indonesia berupa pemukulan yang dilakukan oleh suami terhadap istri.(Muhajarah, 2016) fakta ini memperlihatkan bahwa keluarga belum dapat memainkan peran pentingnya sebagai lembaga pendidikan awal, yang diharapkan dapat membentuk watak dan kepribadian manusia seutuhnya. Hal inilah yang mendorong penulis untuk melakukan peninjauan mengenai konteks pendidikan keluarga.

\section{Metode}

Jenis penelitian ini tergolong penelitian pustaka (library research), karena semua yang digali adalah bersumber dari pustaka. Untuk pengumpulan data dalam penelitian ini digunakan metode dokumentasi, yaitu mencari data catatan, buku, jurnal dan majalah. Dalam analisis data kualitatif, metode yang digunakan untuk membahas sekaligus sebagai kerangka berpikir pada penelitian ini adalah metode Analisis Konteks,(Rahmawati, 2016) yaitu suatu usaha untuk mengumpulkan dan menyusun data, kemudian diusahakan pula dengan analisa dan interpretasi atau penafsiran terhadap data-data tersebut. 


\section{Hasil dan Pembahasan}

\section{Pengertian Pendidikan}

Dalam Kamus Besar Bahasa Indonesia dijelaskan bahwa pendidikan(Sudaryanto, 2020) adalah proses pengubahan sikap dan tata laku seseorang atau kelompok orang dalam usaha mendewasakan manusia melalui upaya pengajaran dan pelatihan.

Dalam konteks Islam istilah pendidikan telah dikenal dengan banyak istilah yang beragam yaitu at-tarbiyah, at-ta'lim, dan at-ta'dib. Dari setiap istilah tersebut mempunyai makna yang berbeda-beda. Walaupun dalam beberapa hal mempunyai arti yang sama.

a. al-Tarbiyah.(Siregar et al., n.d.) Kata tarbiyah berasal dari kata "rabba-yurabbitarbiyatan" yang berarti memelihara, mendidik, mengasuh. Menurut Ibnu Abdillah Muhammad bin Ahmad al Anshari al Qurthubi mengartikan bahwa rabb adalah pemilik, maha memperbaiki, maha mengatur, maha menambah, maha menunaikan. Sedangkan menurut al-Jauhari adalah memberi makan, memelihara, mengasuh. Dalam al-Qur'an kata "rabba" ini digunakan untuk Tuhan, karena Tuhan sifatnya mendidik, mengasuh, memelihara dan pencipta. Tarbiyah menurut Ibnu Qoyyim al- Jauziyah,(Haqiqi, 2019) mencakup tarbiyah qalb (pendidikan hati) dan tarbiyah badan secara sekaligus. Dan beliau menjelaskan kaifiyah (cara) mentarbiyah hati dan badan tersebut. Beliau berkata “ Antara hati dan badan sama-sama membutuhkan kepada tarbiyah. Keduanya harus ditumbuhkembangkan dan ditambah gizinya sehingga mampu tumbuh dengan sempurna dan lebih baik dari sebelumnya.

b. al-Ta'lim. Kata ta'lim (Ma'zumi et al., 2019)berasal dari kata 'allama yang berarti proses transmisi ilmu pengetahuan atau sama dengan pengajaran, yang sering disebut dengan transfer of knowledge. Menurut Naquib al-Attas adalah proses pengajaran tanpa adanya pengenalan secara mendasar yaitu memberikan atau mengajarkan suatu ilmu pengetahuan kepada peserta didik.

c. al-Ta'dib.(Syah, 2017) Kata al-ta'dib berasal dari kata 'Adaba yang berarti bersopan santun atau beradab. Seseorang dalam menuntut ilmu harus mempunyai sopan santun agar ilmu sedang dipelajari bisa bermanfaat dan diridhoi oleh Allah Ta'ala. Menurut Naquib al Attas ta'dib (Suhandi, 2020)adalah proses mengenalkan ilmu pengetahuan secara berangsur angsur kepada diri manusia dalam tatanan penciptaan, kemudian membimbing dan mengarahkannya pada pengakuan dan pengenalan kekuasaan, keagungan Allah Ta'ala di dalam tatanan wujud dan keberadaannya.

Dari uraian pengertian tentang pendidikan tersebut, dapat dipahami bahwa pendidikan merupakan upaya membimbing, membina dan mengarahkan agar anak mendapatkan kebaikan-kebaikan yang bermanfaat bagi dirinya dalam mempersiapkan serta menjalani kehidupan.

\section{Tujuan Pendidikan Keluarga}

Islam memberikan petunjuk terkait tujuan dalam pendidikan keluarga, sebagaimana firman Allah Ta'ala yang artinya "Wahai orang-orang yang beriman jagalah diri kalian dan keluarga kalian dari api neraka" (QS at-Tahrim: 6). "Wahai orang-orang yang percaya kepada Allah dan rasul-Nya serta menjalankan syariat-Nya jagalah diri kalian dengan mengamalkan apa yang Allah peritahkan dan meninggalkan apa yang Allah larang. Demikian juga jagalah isterimu dengan cara yang sama yang kalian gunakan untuk menjaga diri kalian sendiri" (atTafsir al-Muyassar hal 560).

Pada ayat di atas terdapat kata quanfusakum yang berarti, buatlah sesuatu yang dapat menjadi penghalang datangnya siksaan api neraka dengan cara menjauhkan perbuatan maksiat. Memperkuat diri agar tidak mengikuti hawa nafsu, dan senantiasa taat menjalankan perintah Allah Ta'ala. Selanjutnya kata wa ahlikum, maksudnya adalah keluargamu yang terdiri dari istri, anak, saudara, kerabat, pembantu dan budak, diperintahkan kepada mereka 
agar menjaganya, dengan cara memberikan bimbingan, nasehat, dan pendidikan kepada mereka. Perintahkan mereka untuk melaksanakannya dan membantu mereka dalam merealisasikannya. Bila melihat ada yang berbuat maksiat kepada Allah Ta'ala, maka cegah dan larang mereka. Ini merupakan kewajiban setiap muslim, yaitu mengajarkan kepada orang yang berada di bawah tanggung jawabnya, segala sesuatu yang telah diwajibkan dan dilarang oleh Allah Ta'ala.

Seseorang yang beriman yang diikuti oleh anak keturunannya juga beriman, maka akan diselamatkan oleh Allah Ta'ala dari siksa api neraka dan dikumpulkan didalam surga, Sebagaimana firman Allah Ta'ala yang artinya "Orang-orang yang beriman yang anak keturunannya mengikutinya dalam masalah iman niscaya akan kami gabungkan anak keturunannya dengannya. Kami tidak akan menelantarkan amal mereka sedikitpun. Setiap orang itu bertanggung jawab dengan amalnya masing-masing" (QS ath-Thur: 21). Ini adalah diantara kesempurnaan nikmat yang dirasakan oleh para penghuni surga. Yaitu Allah satukan dengan mereka anak keturunannya yang mengikutinya dalam iman. Mereka ini akan Allah satukan dengan orang tuanya dalam posisi di surga meskipun sebenarnya posisi anak keturunan tersebut tidak sampai posisi tersebut sebagai balasan untuk orang tuanya dan tambahan ganjaran bagi orang tua. Meski demikian Allah tidak mengurangi amal orang tua sedikit pun. Setelah membaca potongan ayat ini boleh jadi ada orang yang memiliki prasangka bahwa penduduk neraka demikian pula keadaannya. Allah gabungkan anak ke posisi orang tuanya di neraka. Oleh karena itu di akhir ayat Allah sampaikan bahwa aturan di neraka dan surga tidaklah sama. Neraka adalah tempat keadilan. Diantara bentuk keadilan Allah adalah Allah tidak akan menyiksa seseorang kecuali karena dosanya sendiri". Hal ini akan bisa tercapai melalui pendidikan dalam keluarga, dimana orang tua harus membimbing, membina, mengajarkan keimanan kepada anak-anaknya.

Guna tercapainya tujuan pendidikan keluarga dibutuhkan kerjasama, saling tolongmenolong dan saling nasehat-menasehati dalam kebaikan dan taqwa diantara anggota keluarga. Sebagaimana firman Allah Ta'ala yang artinya "Dan hendaknya kalian bekerjasama dalam kebaikan dan takwa dan jangan bekerja sama dalam dosa dan tindakan melampaui batas" (QS al-Maidah: 2). "Kerja sama dalam kebaikan dan takwa artinya kerja sama dalam mengikuti perintah dan menjauhi hawa nafsu. Yang dimaksud dengan 'dosa' adalah maksiat dalam rangka memuaskan selera. Sedangkan yang dimaksud dengan 'melampaui batas' adalah melanggar batasan Allah dalam membalas" (Murah Labib Tafsir anNawawi 1/189).

Dari Tsauban, tatkala turun ayat yang berisi celaan menyimpan emas dan perak banyak orang yang bertanya-tanya, "Harta seperti apa yang sebaiknya kita miliki?". Umar mengatakan, "Akan kuberitahukan kepada kalian jawaban pertanyaan tersebut". Umar lantas menunggangi ontanya. Umar berhasil menyusul Nabi dan aku berada di belakang Umar. Umar bertanya, "Wahai Rasulullah harta seperti apa yang sebaiknya kami miliki?" Jawaban Nabi, "Hendaknya kalian memiliki harta yang bersyukur, lidah yang sering berdzikir dan isteri yang beriman yang membantu suaminya dalam masalah akherat" (HR Ibnu Majah). "Maksudnya membantu agama suami dengan mengingatkan suami untuk mengerjakan shalat, puasa dan ibadah lainnya dan mencegah suami untuk melakukan zina dan berbagai hal yang haram selainnya" (Tuhfah al-Ahwadzi 8/390).

Dari Abu Umamah, Rasulullah bersabda kepada Muadz bin Jabal, "Wahai Muadz, hati yang bersyukur, lidah yang berdzikir dan isteri sholihah yang membantumu sukses dunia dan akherat adalah sebaik-baik harta simpanan milik manusia" (HR al-Baihaqi dalam Syuabul Iman). Dari Abu Hurairah, Rasulullah bersabda, "Semoga Allah melimpahkan kasih sayangNya kepada seorang suami yang bangun di waktu malam lantas shalat malam dan membangunkan isterinya. Jika isteri tidak mau bangun dipercikkannya air ke wajah isterinya. Demikian pula semoga Allah melimpahkan kasih sayang-Nya kepada seorang isteri yang bangun di waktu malam lantas shalat malam dan membangunkan suaminya. Jika suami tidak mau bangun dia percikkan air ke wajah suaminya" (HR Abu Daud). 
Dari Aisyah, adalah Rasulullah jika shalat malam dan hendak mengerjakan shalat Witir beliau berkata, "Wahai Aisyah, ayo bangun kerjakan sholat Witir" (HR Muslim).

\section{Keluarga Tempat Berlindung Dari Dosa}

Dari Tsauban, bekas budak Rasulullah, Nabi bersabda, "Sungguh beruntung bagi siapa saja yang menguasai lisannya, merasa nyaman dan betah di rumah dan menangisi dosadosanya" (HR Thabarani dalam al-Mu'jam al-Ausath dan alMu'jam ash-Shaghir).

Dari Muadz, Rasulullah mewasiatkan lima hal kepada kami. Siapa saja yang melakukan hal tersebut Allah akan memberikan jaminan baginya (untuk masuk surga dan selamat dari neraka). Lima hal tersebut adalah membezuk orang sakit, mengiringi jenazah ke pemakaman, berangkat perang di jalan Allah, menemui penguasa muslim untuk menghormati dan memuliakannya atau duduk manis di rumah sehingga manusia selamat dari gangguannya dan dia selamat dari gangguan orang lain (HR Ahmad). Nabi bersabda, "Kunci keselamatan seseorang dari hal-hal yang merusak iman adalah betah tinggal di rumah" (HR ad-Dailami dalam Musnad al-Firdaus, dinilai hasan oleh al-Albani).

Dari Abu Barzah al-Aslamy, Rasulullah bersabda, "Dua telapak kaki seorang hamba pada hari Kiamat itu tidak akan bergeser hingga ditanyai mengenai umurnya untuk apa dia habiskan, ilmunya apa yang sudah diamalkan, hartanya dari mana dia dapatkan dan untuk keperluan apa saja dia habiskan dan badannya untuk keperluan apa saja dia rusakkan" (HR Tirmidzi).

Dari Kaab bin Ujrah, Rasulullah bersabda, "Jika engkau punya penguasa maka siapa yang menemuinya dan membenarkan kebohongannya dan membantu kezalimannya maka dia bukanlah bagian dariku dan aku pun bukan bagian darinya. Dia tidak akan mendatangi telaga. Sebaliknya siapa yang menemuinya namun tidak percaya dengan kebohongannya dan tidak membantu kezalimannya maka dia adalah bagian dariku dan aku adalah bagian darinya. Wahai Kaab bin Ujrah, sungguh tidak akan masuk surga daging dan darah yang tumbuh dari harta yang haram. Nereka adalah tempat yang terbaik untuknya. Wahai Kaab bin Ujrah, manusia itu ada dua macam. Ada yang berupaya untuk menyelamatkan diri dan ada yang mencelakakan dirinya sendiri. Wahai Kaab bin Ujrah, sholat itu bukti iman sedangkan puasa adalah perisai" (HR Thabarani dalam al-Mu'jam al-Kabir). Kebiasaan wanita di masa salaf, jika ada seorang laki-laki yang mau keluar rumah berangkat kerja maka isteri atau anak perempuannya mengatakan, "Hindari pendapatan haram. kami masih kuat untuk menghadapi lapar dan derita namun kami tidak akan kuat menghadapi siksa neraka" [Ihya Ulumuddin 2/67].

Ahmad bin Hafsh mengatakan bahwa beliau menemui Abul Hasan Ismail, ayah dari Abu Abdillah saat beliau hendak meninggal dunia. Beliau mengatakan, "Aku tidak tahu pada hartaku ada satu dirham dari sumber yang haram atau pun satu dirham dari sumber yang syubhat". Ahmad mengatakan, "Saat itulah aku merasa hina di hadapan diriku sendiri". Abu Abdillah al Bukhari mengatakan, "Perkataan yang paling benar yang diucapkan oleh seseorang adalah di saat kematiannya" (Siyar A'lam an-Nubala' 12/447). "Sungguh harta itu hijau dan manis. Siapa yang mengambilnya dengan tanpa kerakusan hartanya akan diberkahi. Namun siapa yang mengambilnya dengan jiwa yang selalu mengharapkannya maka harta tersebut tidak ada berkahnya seperti orang yang makan namun tidak kunjung kenyang" (HR Bukhari dan Muslim)

\section{Urgensi Kumpul Keluarga}

Dari Abu Hurairah, Nabi bersabda, "Safar itu potongan adzab. Safarlah yang menghalangi seorang untuk bisa menikmati makanan, minuman dan tidurnya. Jika seorang musafir sudah menyelesaikan urusannya hendaknya dia segera kembali kepada keluarganya" (HR Bukhari dan Muslim). "Pulanglah kepada keluargamu. Tinggallah di tengah-tengah mereka. Ajari dan perintahkan mereka" (HR Bukhari). Dari Ibnu Abbas, Nabi bersabda, "Sebaik-baik kalian 
adalah yang paling baik dengan isterinya dan aku adalah sebaik-baik kalian dengan isteriisteriku" (HR Ibnu Majah). Nabi bersabda, "Perhatikanlah bagaimana sikapmu dengan suamimu. Perlakuan terhadap suami itu menentukan surga dan nerakamu" (HR Ahmad). "Siapa yang ingin dijauhkan dari neraka dan dimasukkan ke dalam surga hendaknya dia meninggal dunia dalam kondisi beriman kepada Allah dan hari akhir dan bersikaplah kepada orang lain dengan sikap yang anda inginkan anda dapatkan dari orang lain" (HR Muslim).

Dari Samurah bin Jundab, Rasulullah bersabda, "Sungguh wanita (baca: Hawa) itu tercipta dari tulang rusuk. Jika anda luruskan dia akan patah. Oleh karena itu pandaipandailah bersikap dengannya niscaya rumah tangga anda akan awet" (HR Ibnu Hibban). Nabi bersabda, "Tidak ada main-main yang bermanfaat kecuali tiga hal. Yaitu aktivitas melatih kuda, canda-canda dengan isteri dan memanah" (HR Nasai).

\section{Simpulan}

Berdasarkan uraian dalam tulisan ini, dapat dipahami bahwa konsep dasar pendidikan keluarga muslim secara umum bertujuan untuk menyelamatkan seluruh anggota keluarga, saling bantu membantu mencapai kebaikan didunia dan diakhirat dalam lingkup keluarga, dimana orang tua (ayah dan ibu) berperan sebagai penggerak. Representasi awal oleh orang tua yang diterima dan diyakini anak sebagai kebenaran dalam keluarganya akan membentuk paradigma mendasar, yang kelak akan menentukan perilaku dan karakter sang anak hingga menjadi dewasa di lingkungan sosialnya. Sehingga esensi yang sangat mendasar dalam pendidikan keluarga muslim ialah melakukan proses penanaman nilai-nilai agama yang dilakukan oleh orang tua kepada anaknya.

\section{Daftar Pustaka}

Cahyani, R., \& Suyadi, S. (2019). Konsep Pendidikan Anak Usia Dini Menurut Ki Hadjar Dewantara. Golden Age: Jurnal Ilmiah Tumbuh Kembang Anak Usia Dini, 3(4), 219-230. https://doi.org/10.14421/jga.2018.34-01

Dirgayunita, A. (2020). Pendidikan Keluarga Sakinah Dalam Perspektif Hukum Islam Dan Psikologi. Imtiyaz, 4(02), 163-164.

Haqiqi, A. A. (2019). Akal, Jiwa, Jasmani \& Akhlak. Journal of Chemical Information and Modeling, 53(9), 1689-1699.

Krisnani, H., \& Kessik, G. (2020). Analisis Kekerasan Seksual Pada Anak dan Intervensinya oleh Pekerjaan Sosial (Studi Kasus Kekerasan Seksual oleh Keluarga di Lampung). Focus : Jurnal Pekerjaan Sosial, 2(2), 198. https://doi.org/10.24198/focus.v2i2.26245

Ma'zumi, M., Syihabudin, S., \& Najmudin, N. (2019). PENDIDIKAN DALAM PERSPEKTIF AL-QUR'AN DAN AL-SUNNAH : Kajian Atas Istilah Tarbiyah, Taklim, Tadris, Ta'dib dan Tazkiyah. TARBAWY: Indonesian Journal of Islamic Education, 6(2), 193-209. https://doi.org/10.17509/t.v6i2.21273

Mawardi, M. (2017). Keluarga Sakinah: Konsep \& Pola Pembinaan. International Journal Ihya' 'Ulum AlDin, 18(2), 253. https://doi.org/10.21580/ihya.17.2.1739

Muhajarah, K. (2016). Kekerasan Terhadap Perempuan dalam Rumah Tangga. Sawwa, 11(2), 127-146.

Rahmawati, I. Y. (2016). Analisis teks dan konteks pada kolom opini "Latihan Bersama Al Komodo 2014" Kompas. Jurnal Dimensi Pendidikan Dan Pembelajaran, 4(1), 49-57.

Safriana, \& Khasanah, N. (2019). Peran Keluarga Sebagai Madrasah Pertama Bagi Pendidikan Ketauhidan Anak. An-Nidzam, 6(1), 89-106.

Sarbini, M. (2017). Pendidikan Keluarga Muslim Dalam Perspektif Fiqih Al-Qur`an. Edukasi Islami : Jurnal Pendidikan Islam, 4(08), 22.

http://jurnal.staialhidayahbogor.ac.id/index.php/ei/article/view/73

Siregar, T. H., Zein, A., \& Nahar, S. (n.d.). Kontribusi Surat an-Nahl Terhadap Metode Pendidikan. 59-74.

Sudaryanto, S. (2020). Kamus Besar Bahasa Indonesia Edisi Kelima Dalam Pembelajaran Bahasa 
Indonesia (Perspektif Filsafat Pendidikan Bahasa). Lateralisasi, 08, 92-99.

http://jurnal.umb.ac.id/index.php/lateralisasi/article/view/1210

Suhandi, S. (2020). Konsep Pendidikan (al-Ta'dib) untuk Membentuk Kepemimpinan Menurut al-Attas. Kalimah: Jurnal Studi Agama Dan Pemikiran Islam, 18(2), 201. https://doi.org/10.21111/klm.v18i2.4870

Suyono, S. (2018). HUKUM KELUARGA:PERSPEKTIF ANTROPOLOGI HUKUM ISLAM. Jurnal Ilmiah AlSyir'ah, 16(1), 58. https://doi.org/10.30984/jis.v16i1.647

Syah, A. (2017). TERM TARBIYAH, TA'LIM DAN TA'DIB DALAM PENDIDIKAN SLAM: Tinjauan dari Aspek Semantik. Al-Fikra : Jurnal Ilmiah Keislaman, 7(1), 138.

https://doi.org/10.24014/af.v7i1.3786 